\title{
Future Trends in Production and Consumption in Textile and Fashion Design: The Fourth Industrial Revolution
}

\author{
Adriana Yumi Sato Duarte* \\ Department of Mechanical Engineering, Nossa Senhora do Patrocinio University, Brazil
}

Received: January 12, 2018; Published: January 18, 2018

*Corresponding author: Adriana Yumi Sato Duarte, Department of Mechanical Engineering, Nossa Senhora do Patrocinio University, Brazil

\section{Opinion}

Designers create products, services and systems to fulfill the society's needs and desires. The adoption of Information Technology (IT) has changed the way designers develop new products. The collaborative work environment is a new paradigm of product design that integrates designers to quickly build, evaluate, optimize and select the best solution to complex problems [1]. In the last 20 years, internet has changed the way people communicate. The first era (1995), internet was an integrated hypermedia, in the second era (2000) internet had a programming media approach, that changed to people's web service in the third era (2005), and the fourth era - which encompasses nowadays - represents a new level of organization and management of the entire value chain on the products' life cycle. The Industrie 4.0 or Fourth Industrial Revolution is an integrative cyber-physical system based on modern control systems, embedded software systems and Internet addresses. This industrial revolution is based on improvement of brainwork, especially in engineering activities, and fast decisionmaking [2].

According to the German Academy of Science and Engineering (Deutsch Akademie der Technnikwissenschaft - Acatech), the Industrie (Industry, in German) 4.0 is the next industrial revolution. The main goal is to improve the value chains among the product's lifecycle. In this context, the improvement of industrial competitiveness is achieved by organizing and controlling value, new business models and networks creation process [3]. The result of the Fourth Industrial Revolution will be the Smart Factory, where Cyber Physical Systems (CPS) and Internet of Things (IoT) are the key technologies for achieving the production goals. In a smart factory, humans, machines and resources communicate with each other as easily as in a social network [4,5].

The CPS interconnects the physical world with the information technology. CPS are technical systems containing both virtual (cyber) and real (physical) systems. By "cyberizing the physical" and "physicalizing the cyber", it is possible to specify physical subsystems with software-controlled behavior [3,6]. The IoT is an approach to equip real systems with embedded systems so that they become interconnected in the so-called "smart systems". The IoT intends to attach technology to devices and to integrate networks with the internet to enable the creation of a global network ubiquitous computing [3].

Kitchin [7] states that data are the key element for our contemporary society. Big Data include information from a multitude of sources, including social media, smart phones, data sharing, sensor-oriented machines and devices for the consumer (wearable computers). The origin of the textile production is closely related to the origin of humanity, and is considered a basic human need. In addition, it is a form of self-expression and sense of belonging that becomes even more important for individuals and social groups [8]. Once this field plays an important role in the Industrial Revolution, the Industrie 4.0 will modify the way clothing are made and consumed.

New management strategies can generate valuable data for product development, online marketing and campaigns. Manufacturing, supply chain and logistics will benefit from the adoption of digital sensors and smart tags that will offer visibility, flexibility and control of product flows. Two production models are examples from those new strategies: smart factory and minifactory. The smart factory integrates stakeholders in a virtual and collaborative environment, while mini-factories are based on ondemand production. The yarn and fabric production processes will be remote monitored using QR Code (Quick Response Code) and RFID (Radio Frequency IDentification).

The steps of cutting and sewing are the biggest problems of textile manufacturing. In this sense, initiatives such as the adoption of artificial intelligence and genetic algorithm, intelligent hybrid systems, robots and fully automated and intelligent lines represent new directions for the textile industry in the context of Industrie 4.0. Smart machines that are able to predict failure or quality problems, and organize their decision-making process and self-optimization are another scenario for the Industrie 4.0 [9].

Internet, Virtual and Augmented Reality will support the buying 
experience. In addition, 3D scanning will provide consumers the opportunity to scan, build a 3D model and begin ordering custom clothing. Technology tends to be incorporate in fibers, yarn, fabrics and clothing in the form of functional materials, which includes biomedical and electronic textiles. The textile production processes offer the possibility of creating a new generation of materials and products, which interact with different electronic devices. It is important to highlight that the textile industry must follow all these innovations that will not only affect production, but also models of education, business, consumer habits and social and cultural aspects in the coming years.

\section{References}

1. Kamrani, Ali K (2008) Collaborative Design Approach in Product Design and Development. In: Collaborative Engineering-theory and practice. Springer, USA, pp. 300.

2. Schuh G, Potente T, Varandani R, Hausberg C, Fränken B (2014) Collaboration moves productivity to the next level. Procedia CIRP 17 3-8.

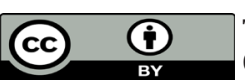

This work is licensed under Creative Commons Attribution 4.0 License

DOI: $10.32474 /$ LTTFD.2018.01.000102
3. Anderl R (2015) Industrie 4.0-technological approaches, use cases, and implementation. at-Automatisierungstech 63(10): 753-765.

4. Sabo F (2015) Industry 4.0-a comparison of the status in Europe and the USA. Austrian Maschall Plan Foundation p. 33.

5. Kagermann H, Wahlster W, Helbig J (2013) Recommendations for implementing the strategic initiative Industrie 4.0: final report of the Industrie 4.0 Working Group p. 82

6. Lee EA (2010) CPS foundations In: Proceedings of the $47^{\text {th }}$ Design Automation Conference. ACM 737-742.

7. Kitchin R (2014) The data revolution: Big data, open data, data infrastructures and their consequences. Sage, UK.

8. Ha-Brookshire J, LaBat K (2015) Envisioning textile and apparel research and education for the $21^{\text {st }}$ Century. International Textile and Apparel Association-ITAA Monography p. 38.

9. Gölzer P,Cato P, Amberg M (2015) Data Processing Requirements of Industry 4.0-Use Cases for Big Data Applications. ECIS 2015 Proceedings.

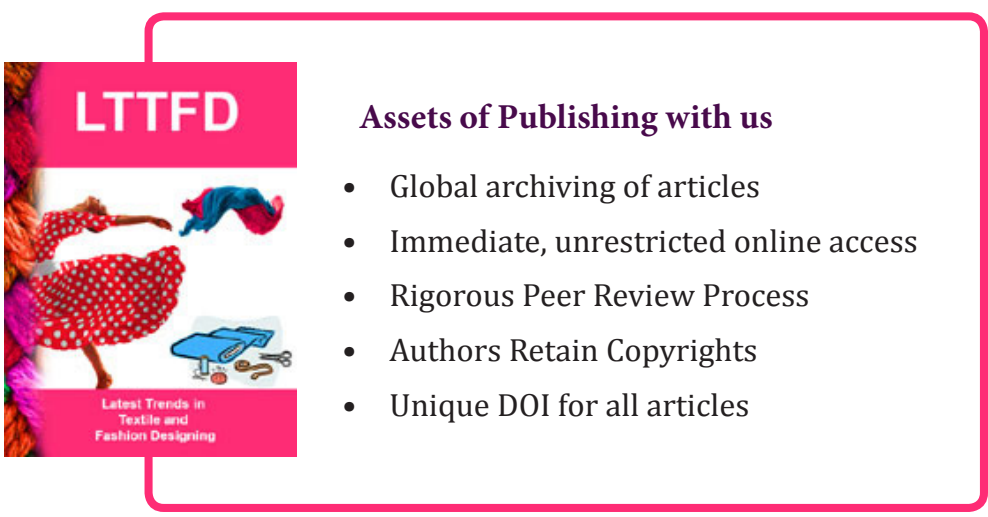

